\title{
Comparison of Long-term Outcomes of Infliximab versus Adalimumab in 1,488 Biologic-Naive Korean Patients with Crohn's Disease
}

\author{
Yoon Suk Jung ${ }^{1}$, Minkyung Han², Sohee Park ${ }^{3}$, and Jae Hee Cheon ${ }^{4}$ \\ ${ }^{1}$ Division of Gastroenterology, Department of Internal Medicine, Kangbuk Samsung Hospital, Sungkyunkwan University School of \\ Medicine, ${ }^{2}$ Biostatistics Collaboration Unit, Department of Biomedical Systems Informatics, Yonsei University College of Medicine, \\ ${ }^{3}$ Department of Biostatistics, Graduate School of Public Health, Yonsei University, and ${ }^{4}$ Department of Internal Medicine and Institute \\ of Gastroenterology, Yonsei University College of Medicine, Seoul, Korea
}

\author{
Article Info \\ Received November 7, 2019 \\ Revised December 7, 2019 \\ Accepted December 15, 2019 \\ Published online August 26, 2020

\section{Corresponding Author} \\ Jae Hee Cheon \\ ORCID https://orcid.org/0000-0002-2282-8904 \\ E-mail GENIUSHEE@yuhs.ac
}

\section{Sohee Park}

ORCID https://orcid.org/0000-0001-8513-5163

E-mail soheepark@yuhs.ac

Yoon Suk Jung and Minkyung Han contributed equally to this work as first authors.
Background/Aims: Data on the comparative effectiveness of infliximab (IFX) or adalimumab (ADA) in patients with Crohn's disease (CD) are rare, particularly for Asian patients. We compared the key clinical outcomes (surgery, hospitalization, and corticosteroid use) of use of these two drugs in biologic-naive Korean patients with CD.

Methods: Using National Health Insurance claims, we collected data on patients who were diagnosed with CD and exposed to IFX or ADA between 2010 and 2016.

Results: We included 1,488 new users of biologics (1,000 IFX users and 488 ADA users). Over a median follow-up period of 2.1 years after starting biological therapy, no significant differences were found between IFX and ADA users in the risks for surgery (ADA vs IFX: adjusted hazard ratio [aHR], 1.22; 95\% confidence interval [Cl], 0.81 to 1.84), hospitalization (aHR, 1.02; 95\% $\mathrm{Cl}, 0.81$ to 1.28$)$, and corticosteroid use (aHR, $0.82 ; 95 \% \mathrm{Cl}, 0.56$ to 1.19). These results were unchanged even when only patients who used biologics for over 6 months were analyzed (aHR [95\% Cl]: surgery, 1.31 [0.82 to 2.11]; hospitalization, 1.02 [0.80 to 1.30]; corticosteroid use, 0.80 [0.54 to 1.18]). Additionally, these results were unchanged in patients treated with biologics as monotherapy or in combination with immunomodulators.

Conclusions: In this nationwide population-based study, no significant difference was found in the long-term effectiveness of IFX and ADA in the real-world setting of biologic-naive Korean patients with $C D$. In the absence of trials to directly compare IFX and ADA, our study indicates that the selection of one of these two biologics can be determined by patient and/or physician preference. (Gut Liver 2021;15:92-99)

Key Words: Crohn disease; Infliximab; Adalimumab

\section{INTRODUCTION}

Crohn's disease $(\mathrm{CD})$ is a longstanding and relapsing inflammatory disease that can affect the entire gastrointestinal tract, often requiring life-long medical treatment. ${ }^{1}$ Biological tumor necrosis factor $\alpha$ (TNF- $\alpha$ ) inhibitors such as adalimumab (ADA) and infliximab (IFX) is one of the most effective drugs, leading to the induction and maintenance of clinical remission in patients with moderate to severe $\mathrm{CD}{ }^{2}$ In addition, some studies have shown that
TNF- $\alpha$ inhibitors have improved the prognoses of patients with CD by preventing structural damage progression, thereby reducing intestinal complications and the need for hospitalization and surgery. ${ }^{2}$ While novel biologics and small molecule drugs are rapidly evolving - with different mechanisms of action from TNF- $\alpha$ inhibitors-TNF- $\alpha$ inhibitors are still considered a milestone in the treatment of $\mathrm{CD}^{2,3}$

Two TNF- $\alpha$ inhibitors-ADA and IFX-were approved for the treatment of CD in South Korea since 2005 and 
2010 , respectively. The main differences between these two drugs are the route of administration (intravenous vs subcutaneous) and the interval between doses ( 2 months vs 2 weeks). Although ADA and IFX were proven in randomized clinical trials (RCTs) to be effective in the treatment of CD compared to placebo, ${ }^{4,5}$ there have been no headto-head comparison trials. Thus, there has been an unmet need among physicians and patients to better understand the relative efficacy of ADA and IFX.

Some network meta-analyses have demonstrated no difference in the rates of induction and maintenance of clinical remission between ADA and IFX. ${ }^{6,7}$ In addition, another network meta-analysis showed no difference in the rates of hospitalization and surgery of $\mathrm{CD}$ between ADA and IFX. ${ }^{8}$ However, indirect comparison through network meta-analysis studies in the absence of head-to-head comparison trials may not be able to detect small differences between ADA and IFX that do exist (type II error may occur). Moreover, very few trials were included in previous network meta-analyses that assessed short-term clinical outcomes within 54 weeks and had restricted inclusion criteria.

Unfortunately, only a few observational studies have compared key clinical outcomes such as surgery and hospitalization between patients with $\mathrm{CD}$ who received ADA and IFX therapy. ${ }^{9-13}$ Furthermore, the results were inconsistent, and most prior studies on this topic have been conducted only in Western countries. ${ }^{9-13}$ Despite an increase in the incidence of CD in Asia, ${ }^{14,15}$ comparative studies of the efficacy of ADA and IFX in Asian patients are extremely scarce. Therefore, we compared the effectiveness of ADA and IFX in biologic-naive patients with $\mathrm{CD}$, using a nationwide population-based study based on South Korean health insurance claims database. To better assess the realworld outcomes of these two TNF- $\alpha$ inhibitors, we compared abdominal surgery, hospitalizations, and the need for corticosteroids.

\section{MATERIALS AND METHODS}

\section{Data source}

The South Korean government operates National Health Insurance program. This is a mandatory nationwide insurance program. Medical institutions submit health care utilization information electronically for reimbursement purposes, and this information is integrated into the Health Insurance Review Agency (HIRA) claims database. The HIRA database contains a wide range of information including principal diagnosis, demographic characteristics, ambulatory care history, procedures, and prescriptions da- tabase and covers the entire population of South Korea. ${ }^{16-18}$ This study was conducted using HIRA database between 2008 and 2016.

\section{Patient identification and data capture}

To improve the diagnostic accuracy of $\mathrm{CD}$, we considered both the appropriate diagnostic codes and CD-related drug prescriptions. ${ }^{16-18}$ The definition of $\mathrm{CD}$ has been described in the previous studies. ${ }^{16-18}$ We used a washout period of 2 years because previous prevalent cases might confound the incidence rate. Accordingly, we were able to analyze patients who were diagnosed with $\mathrm{CD}$ and received biological therapy between January 1, 2010, and December 31, 2016. Patients who were exposed to both ADA and IFX and patients with a history of abdominal surgery before starting biological therapy were excluded.

The primary outcomes of our study were abdominal surgery, hospitalizations, and the need for corticosteroids. Abdominal surgery was identified by using the procedural code for major surgery. Appendectomy (Q2861, Q2862, and Q2863) was not included in the definition of abdominal surgery. Hospitalizations were defined as cases where the patient was admitted to the department of gastroenterology for 3 days or more. New corticosteroid use was defined as moderate- or high-dose corticosteroid use $(\geq 200$ $\mathrm{mg}$ hydrocortisone, $\geq 50 \mathrm{mg}$ methylprednisolone, or $\geq 30$ $\mathrm{mg}$ prednisolone) two months after the first biologics prescription.

We considered surgical history of perianal diseases. Surgical history of perianal diseases was defined as the presence of surgical procedure codes for anal fissure (Q2950), anal fistula (Q2974, Q2975, Q2976 Q2977, Q2978, and Q2979), and periproctal abscess (Q2881, Q2882, and Q2883) before starting biological therapy.

\section{Statistical analysis}

For each IFX and ADA user group, the crude risk of outcomes was described by log-rank tests and the KaplanMeier method. In Cox proportional hazards models, potential confounding variables were adjusted. Gender, the period from $\mathrm{CD}$ diagnosis to first biologics use, age, region, hospital scale, steroids use at the time of first biologics use, and surgical history of perianal diseases were adjusted as time-fixed covariates. Concomitant medications (immunomodulators and 5-aminosalicylic acid) and the use period of cumulative biologics were adjusted as timedependent covariates.

We conducted a sensitivity analysis on patients who used biologics for over 6 months. We also conducted a stratified analysis based on the use of TNF- $\alpha$ inhibitors monotherapy or combination therapy (concomitant use of 
immunomodulators). TNF- $\alpha$ inhibitors-based combination therapy was defined as prescriptions of immunomodulators within 30 days before and/or after the biologics start date. ${ }^{12,13}$ p-values $<0.05$ were considered statistically significant. All analyses were performed using the SAS Enterprise Guide (SAS Institute, Inc., Cary, NC, USA).

\section{Ethical considerations}

This study protocol was approved by the Institutional Review Board (IRB) of Severance Hospital, Yonsei University College of Medicine (IRB number: 4-2017-0927). This study is a retrospective study using medical record review and so informed consent was waived.

\section{RESULTS}

\section{Patient characteristics}

A total of 8,974 patients diagnosed with $\mathrm{CD}$ were identified. Of these patients, 1,838 started their first TNF- $\alpha$ inhibitors during the study period. Of these 1,838 patients, 153 were excluded due to overlapping IFX and ADA use, and 197 were excluded due to abdominal surgery before the start of TNF- $\alpha$ inhibitors. Ultimately, 1,488 patients were included in the study. Of these 1,488 patients, 1,000 were treated with IFX and 488 were treated with ADA as their first TNF- $\alpha$ inhibitors. The median follow-up period was 2.1 years (interquartile range, 1.0 to 3.5 years).

The demographic characteristics of the study population are shown in Table 1. The mean period from CD diagnosis to first biologics use in IFX users was shorter than in ADA users $(1.4 \pm 1.5$ years vs $1.7 \pm 1.5$ years, $\mathrm{p}<0.001)$, whereas the mean period of biologics use in IFX users was longer than in ADA users (2.3 \pm 1.7 years vs $1.8 \pm 1.3$ years, $\mathrm{p}<0.001)$. The rate of steroid use in IFX users was higher than in ADA users $(28.3 \%$ vs $13.9 \%, \mathrm{p}<0.001)$, while the rate of concomitant immunomodulators use was not different between IFX and ADA users $(73.4 \%$ vs $76.8 \%$, $\mathrm{p}=0.171$ ). Surgical history of perianal diseases before biologics use in IFX users was higher than in ADA users $(6.4 \%$ vs $2.3 \%, \mathrm{p}<0.001)$.

\section{Comparative effectiveness of ADA versus IFX}

There were no significant differences in the cumulative rates of abdominal surgery $(\mathrm{p}=0.089)$ (Fig. 1A), hospitalization $(\mathrm{p}=0.209)$ (Fig. 1B), and corticosteroid use $(\mathrm{p}=0.450)$ (Fig. 1C) between IFX and ADA users. At 1 year, 3 years, and 5 years after the first biologics start, the cumulative rates of surgery were $4.6 \%, 8.0 \%$, and $11.8 \%$, respectively, for IFX users, and $6.3 \%, 9.6 \%$, and $12.2 \%$, respectively, for ADA users. The cumulative rates of hospitalization were $17.9 \%, 30.1 \%$, and $36.2 \%$, respectively, for IFX users, and

Table 1. Baseline Characteristics of the Study Population

\begin{tabular}{|c|c|c|c|}
\hline Characteristics & Infliximab users $(\mathrm{n}=1,000)$ & Adalimumab users (n=488) & $\mathrm{p}$-value \\
\hline Male sex & $694(69.4)$ & $357(73.2)$ & 0.152 \\
\hline Age at diagnosis of $C D, y r$ & $25.0 \pm 11.4$ & $25.4 \pm 10.8$ & 0.449 \\
\hline Age at first biologics use, yr & $26.4 \pm 11.4$ & $27.2 \pm 10.9$ & 0.175 \\
\hline The period from CD diagnosis to first biologics use, $\mathrm{yr}$ & $1.4 \pm 1.5$ & $1.7 \pm 1.5$ & $<0.001$ \\
\hline The period of biologics use, yr & $2.3 \pm 1.7$ & $1.8 \pm 1.3$ & $<0.001$ \\
\hline Less than 6 mo & $166(16.6)$ & $75(15.4)$ & 0.596 \\
\hline More than 6 mo & $834(83.4)$ & $413(84.6)$ & \\
\hline \multicolumn{4}{|l|}{ Region at first biologics use } \\
\hline Seoul & $454(45.4)$ & $223(45.7)$ & 0.958 \\
\hline Outside Seoul & $546(54.6)$ & $265(54.3)$ & \\
\hline \multicolumn{4}{|l|}{ Hospital scale at first biologics use } \\
\hline Tertiary hospitals & 718 (71.8) & 355 (72.8) & 0.749 \\
\hline General hospitals/community hospitals/clinics & $282(28.2)$ & $133(27.2)$ & \\
\hline \multicolumn{4}{|l|}{ Medication use at first biologics use } \\
\hline 5-ASAs & $571(57.1)$ & $292(59.8)$ & 0.343 \\
\hline Steroids & $283(28.3)$ & 68 (13.9) & $<0.001$ \\
\hline Immunomodulators & $545(54.5)$ & $281(57.6)$ & 0.286 \\
\hline \multicolumn{4}{|l|}{ Concomitant immunomodulators ( \pm 30 day) } \\
\hline No & $266(26.6)$ & $113(23.2)$ & 0.171 \\
\hline Yes & $734(73.4)$ & $375(76.8)$ & \\
\hline Surgical history of perianal diseases before biologics use* & 64 (6.4) & $11(2.3)$ & $<0.001$ \\
\hline
\end{tabular}

Data are presented as number (\%) or mean \pm SD.

CD, Crohn's disease; 5-ASA, 5-aminosalicylic acid.

*Surgical history of perianal diseases was defined as the presence of surgical procedure codes for anal fissure (Q2950), anal fistula (Q2974, Q2975, Q2976, Q2977, Q2978, and Q2979), and perirectal abscess before biologic use (Q2881, Q2882, and Q2883). 

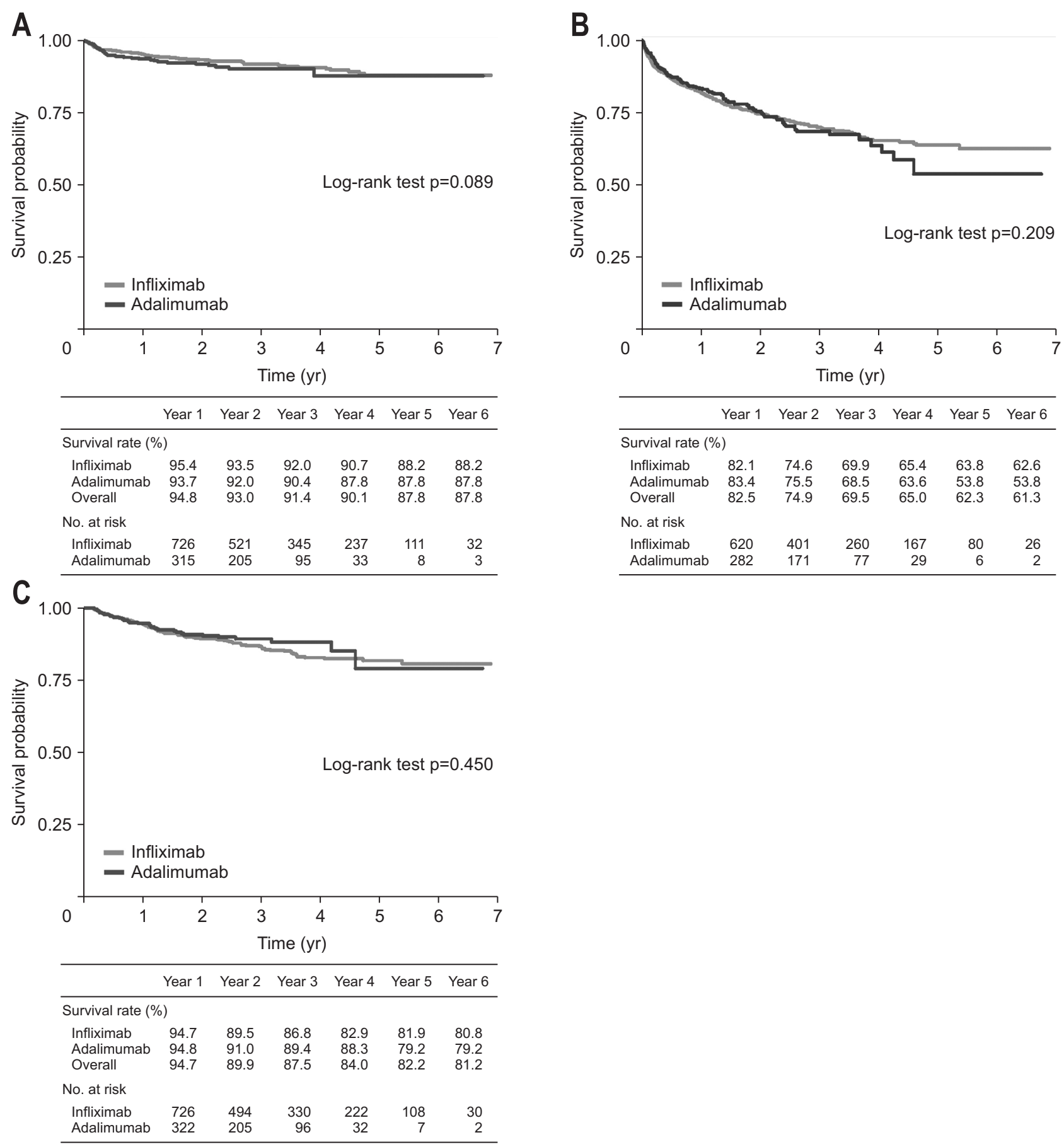

Fig. 1. Survival rates without (A) abdominal surgery, (B) hospitalization, and (C) new corticosteroid use.

$16.6 \%, 31.5 \%$, and $46.2 \%$, respectively, for ADA users. For corticosteroid use, the cumulative rates at 1,3 and 5 years were $5.3 \%, 13.2 \%$, and $18.1 \%$, respectively, for IFX users, and $5.2 \%, 10.6 \%$, and $20.8 \%$, respectively, for ADA users.

Even after adjusting for confounding variables, there were no significant differences in the risk of surgery (adjusted hazard ratio [aHR], 1.22; 95\% confidence interval [CI], 0.81 to 1.84 ), hospitalizations (aHR, 1.02; 95\% CI,
0.81 to 1.28 ), and corticosteroid use (aHR, 0.82; 95\% CI, 0.56 to 1.19 ) between the two groups (Table 2).

\section{Sensitivity analysis and stratified analysis}

In sensitivity analysis of patients who used biologics for over 6 months, we also observed no significant differences in the risk of surgery (aHR, 1.31; 95\% CI, 0.82 to 2.11 ), hospitalizations (aHR, 1.02; 95\% CI, 0.80 to 1.30 ), and cor- 
Table 2. Comparative Effectiveness of Adalimumab versus Infliximab in Biologic-Naive Patients with CD

\begin{tabular}{|c|c|c|c|c|c|c|}
\hline \multirow[b]{2}{*}{ Outcomes } & \multicolumn{2}{|c|}{ Adalimumab } & \multicolumn{2}{|r|}{ Infliximab } & \multicolumn{2}{|c|}{ Adalimumab vs Infliximab } \\
\hline & $\begin{array}{l}\text { No. of } \\
\text { events }\end{array}$ & $\begin{array}{c}\text { Incidence rate, } \\
\text { per 100-py }(95 \% \text { CI) }\end{array}$ & $\begin{array}{l}\text { No. of } \\
\text { events }\end{array}$ & $\begin{array}{c}\text { Incidence rate, } \\
\text { per 100-py (95\% CI) }\end{array}$ & $\begin{array}{l}\text { Adjusted HR } \\
(95 \% \mathrm{CI})^{*}\end{array}$ & $\mathrm{p}$-value \\
\hline \multicolumn{7}{|l|}{ Overall biologics users } \\
\hline Abdominal surgery & 37 & $4.9(3.5-6.6)$ & 72 & $4.2(3.3-5.2)$ & $1.22(0.81-1.84)$ & 0.345 \\
\hline CD-related hospitalization & 115 & $15.2(12.6-18.2)$ & 255 & $14.8(13.1-16.7)$ & $1.02(0.81-1.28)$ & 0.889 \\
\hline New steroid use (after $2 \mathrm{mo}$ ) & 39 & $5.2(3.7-7.0)$ & 111 & $6.5(5.3-7.7)$ & $0.82(0.56-1.19)$ & 0.296 \\
\hline \multicolumn{7}{|l|}{ Biologics users over 6 months } \\
\hline Abdominal surgery & 29 & $4.1(2.8-5.8)$ & 51 & $3.2(2.4-4.2)$ & $1.31(0.82-2.11)$ & 0.259 \\
\hline CD-related hospitalization & 101 & $14.3(11.7-17.2)$ & 224 & $14.1(12.4-16.1)$ & $1.02(0.80-1.30)$ & 0.855 \\
\hline New steroid use (after $2 \mathrm{mo}$ ) & 36 & $5.1(3.6-6.9)$ & 104 & $6.6(5.4-7.9)$ & $0.80(0.54-1.18)$ & 0.265 \\
\hline
\end{tabular}

$\mathrm{CD}$, Crohn's disease; py, person-years; $\mathrm{Cl}$, confidence interval; $\mathrm{HR}$, hazard ratio.

*Adjusted for sex, age at first biologic use, time from CD diagnosis to first biologic use, region, hospital scale, and medication use (5-aminosalicylic acid, immunomodulators, and steroids) at first biologic use, cumulative duration of biologic use, and surgical history of perianal diseases.

Table 3. Comparative Effectiveness of Adalimumab versus Infliximab in Biologic-Naive Patients with CD Stratified by the Use of TNF- $\alpha$ Inhibitors as Monotherapy and in Combination with Immunomodulatory Therapy

\begin{tabular}{|c|c|c|c|c|c|c|}
\hline \multirow[b]{2}{*}{ Outcomes } & \multicolumn{2}{|c|}{ Adalimumab } & \multicolumn{2}{|r|}{ Infliximab } & \multicolumn{2}{|c|}{ Adalimumab vs Infliximab } \\
\hline & $\begin{array}{l}\text { No. of } \\
\text { events }\end{array}$ & $\begin{array}{c}\text { Incidence rate, } \\
\text { per } 100 \text {-py }(95 \% \text { Cl) }\end{array}$ & $\begin{array}{l}\text { No. of } \\
\text { events }\end{array}$ & $\begin{array}{c}\text { Incidence rate, } \\
\text { per } 100 \text {-py }(95 \% \text { Cl) }\end{array}$ & $\begin{array}{l}\text { Adjusted HR } \\
\left(95 \% \mathrm{Cl}^{*}\right.\end{array}$ & p-value \\
\hline \multicolumn{7}{|c|}{ TNF- $\alpha$ inhibitors monotherapy ( $n=379$ ) } \\
\hline \multicolumn{7}{|l|}{ Overall biologics users } \\
\hline Abdominal surgery & 13 & $7.1(3.9-11.7)$ & 24 & $5.2(3.4-7.5)$ & $1.39(0.68-2.85)$ & 0.364 \\
\hline CD-related hospitalization & 30 & $16.4(11.2-22.9)$ & 69 & $14.9(11.6-18.7)$ & $1.17(0.75-1.84)$ & 0.488 \\
\hline New steroid use (after 2 mol & 13 & $7.1(3.5-11.0)$ & 37 & $8.0(5.7-10.8)$ & $0.98(0.51-1.87)$ & 0.938 \\
\hline \multicolumn{7}{|l|}{ Biologics users over 6 mo } \\
\hline Abdominal surgery & 12 & $7.0(3.7-11.7)$ & 16 & $3.9(2.3-6.1)$ & $2.05(0.92-4.57)$ & 0.079 \\
\hline CD-related hospitalization & 25 & $14.5(9.6-21.0)$ & 58 & $14.0(10.7-17.9)$ & $1.13(0.69-1.85)$ & 0.621 \\
\hline New steroid use (after 2 mol & 13 & $7.6(4.2-12.4)$ & 33 & $8.0(5.5-11.0)$ & $1.05(0.54-2.03)$ & 0.894 \\
\hline \multicolumn{7}{|c|}{ TNF- $\alpha$ inhibitors+immunomodulatory therapy $(n=1,109)$} \\
\hline \multicolumn{7}{|l|}{ Overall biologics users } \\
\hline Abdominal surgery & 24 & $4.2(2.7-6.1)$ & 48 & $3.8(2.8-5.0)$ & $1.17(0.71-1.94)$ & 0.542 \\
\hline CD-related hospitalization & 85 & $14.9(11.9-18.2)$ & 186 & $14.8(12.8-17.1)$ & $0.98(0.75-1.28)$ & 0.871 \\
\hline New steroid use (after $2 \mathrm{mo}$ ) & 26 & $4.5(3.0-6.5)$ & 74 & $5.9(4.7-7.3)$ & $0.82(0.52-1.30)$ & 0.395 \\
\hline \multicolumn{7}{|l|}{ Biologics users over 6 mo } \\
\hline Abdominal surgery & 17 & $3.2(1.9-4.9)$ & 35 & $3.0(2.1-4.1)$ & $1.07(0.59-1.96)$ & 0.818 \\
\hline CD-related hospitalization & 76 & $14.2(11.2-17.6)$ & 166 & $14.2(12.1-16.4)$ & $1.00(0.75-1.32)$ & 0.970 \\
\hline New steroid use (after 2 mol & 23 & $4.3(2.8-6.3)$ & 71 & $6.1(4.8-7.6)$ & $0.77(0.47-1.24)$ & 0.279 \\
\hline
\end{tabular}

$\mathrm{CD}$, Crohn's disease; TNF, tumor necrosis factor; py, person-years; $\mathrm{Cl}$, confidence interval; HR, hazard ratio.

*Adjusted for sex, age at first biologic use, time from CD diagnosis to first biologic use, region, hospital scale, and medication use (5-aminosalicylic acid, immunomodulators, and steroids) at first biologic use, cumulative duration of biologic use, and surgical history of perianal diseases.

ticosteroid use (aHR, 0.80 ; 95\% CI, 0.54 to 1.18 ) between IFX and ADA users (Table 2). In addition, there were no significant differences for the three outcomes between ADA and IFX users with either TNF- $\alpha$ inhibitors monotherapy or combination therapy (Table 3 ).

\section{DISCUSSION}

In this study of 1,488 biologic-naive Korean CD patients, we observed that IFX and ADA were comparable in terms of risk of major abdominal surgery, CD-related hospitalization, and new initiation of corticosteroids. These results were unchanged even when analyzed for patients who used biologics for over 6 months. In addition, these results were the same for patients treated with biological monotherapy or combination therapy. Our findings demonstrate that IFX and ADA are comparable in their real-world CDrelated outcomes.

Surgery and hospitalization signal severe disease and are an important cause of morbidity in patients with $\mathrm{CD} .{ }^{19} \mathrm{Up}$ to two-thirds of patients with $\mathrm{CD}$ require at least one $\mathrm{CD}$ - 
related surgery or medical hospitalization. ${ }^{19-21}$ In addition, a significant portion of $\mathrm{CD}$-related costs are attributable to medical or surgical hospitalization. ${ }^{22}$ While several RCTs have shown the efficacy of IFX and ADA in achieving induction and maintenance of clinical remission compared to placebo, the data on the effect of such therapies on modification of natural history, such as reduction in surgery and hospitalization, is scarce. Accordingly, prior network meta-analyses examining comparative effectiveness among biologics have focused on clinical response and remission. Network meta-analyses by Stidham et al. ${ }^{7}$ and Hazlewood et al. ${ }^{6}$ have shown no difference between IFX and ADA in influencing the induction and maintenance of clinical remission in CD. However, the network analysis by Singh et al. ${ }^{23}$ ranked IFX as the most efficacious agent for induction and ADA for maintenance of remission. Recently, a network meta-analysis by Mao et al. ${ }^{8}$ focused on the comparative efficacy of biologics for reducing surgery and hospitalization. The study revealed that TNF- $\alpha$ inhibitors significantly reduced surgery and hospitalization compared to placebo, with no significant differences between IFX and ADA. ${ }^{8}$ However, RCTs included in this network meta-analysis study were extremely few in number (2 IFX studies and 1 ADA study). Moreover, these results were based on indirect comparisons.

To our knowledge, this is the first nationwide population-based study to compare the long-term outcomes of ADA and IFX in Korean CD patients. To date, several observational studies have conducted head-to-head comparisons of ADA and IFX in CD patients. However, the majority of these studies have been conducted in Western countries, and studies on this topic in Asian patients have been rarely conducted. Several Western studies have shown no difference in clinical response and remission between these two TNF- $\alpha$ inhibitors. ${ }^{24-27}$ Similar to our results, some studies from Western countries have shown no difference in the risk of surgery, hospitalization, and steroid utilization between IFX and ADA..$^{9-11,13,26,28}$ A retrospective cohort study using U.S. Medicare data showed no significant difference in the risks of abdominal surgery and hospitalization between IFX- and ADA-treated patients with $\mathrm{CD}\left(\mathrm{n}=1,459\right.$ and $\mathrm{n}=871$, respectively). ${ }^{10}$ A U.S. study revealed no difference in surgery, hospitalizations or prednisone use within 1 year after initiation of ADA $(n=309)$ or IFX ( $\mathrm{n}=723)$ for $\mathrm{CD} .{ }^{11}$ In another U.S. study using a large healthcare database, emergency room visits and hospitalizations within 6 months of TNF- $\alpha$ inhibitors initiation were not statistically different between IFX and ADA users, although healthcare costs were significantly lower in ADA users $(n=623)$ compared with IFX users $(n=623){ }^{28}$ A Canadian study also demonstrated that the rates of sur- gery, hospitalizations or need for steroids after 12 weeks of therapy were similar between ADA users $(\mathrm{n}=77)$ and IFX users $(n=143) .{ }^{26}$ In addition, a recent study based on health administrative databases from Italy reported that the risks of steroid utilization, abdominal surgery, and hospitalization for infection were not different between ADA and IFX new users with $\mathrm{CD}\left(\mathrm{n}=367\right.$ and $\mathrm{n}=505$, respectively). ${ }^{9}$ Similarly, in a Danish nationwide population-based cohort study of 827 biologic-naive patients, there were no significant differences in the rate of CD-related hospitalization, major abdominal surgery, and corticosteroid use between patients treated with IFX and ADA $(n=512$ and $n=315$, respectively). ${ }^{13}$ However, in contrast to our findings, a U.S. administrative claims-based study reported a lower risk of abdominal surgery, hospitalization, and corticosteroid use in patients treated with IFX $(n=1,427)$ compared with those treated with $\operatorname{ADA}(n=1,248) .{ }^{12}$

In summary, most of the previous studies as well as our study have shown no difference in the clinical efficacy between IFX and ADA. We conducted a sensitivity analysis in order to further compare the long-term effects of IFX and ADA in patients who used biologics for 6 months or more; this also showed no difference in the outcomes between the two biologics. In the absence of RCTs comparing these two TNF- $\alpha$ inhibitors directly, our findings support that the choice of either of ADA or IFX may be left to the preference of the patient and/or physician.

This study had several limitations. First, this was a retrospective and observational study, not an interventional study; thus, there may be confounding factors that are not measured across groups. The potential for confounding due to disease severity can be particularly problematic because administrative data do not include information on disease severity such as clinical, biochemical, or endoscopic activity. However, this may not have a significant effect on our results, since TNF- $\alpha$ inhibitors are commonly used for similar levels of disease activity (moderate to severe activity). Furthermore, IFX and ADA were approved only for patients with a CD Activity Index of 220 or higher in South Korea. In addition, steroid use at the time of the first biologics use can reflect the patient's disease activity, which was adjusted in our study. Second, we were also not able to assess the effect of dose escalation or interval shortening, which are strategies to improve the effectiveness of biologics. There is no information on the weight of patients in the HIRA database. Therefore, it was difficult to accurately capture whether the IFX dose was doubled and when it was doubled in each of the 1,000 IFX users. In the case of ADA, a self-injectable drug, it was also difficult to accurately capture the shortening of interval because the timing of prescription and actual administration might have been 
different. Given these limitations, we were not able to analyze the data on dose escalation and interval shortening. Third, the efficacy of ADA and IFX in remission induction and maintenance could not be compared because information on disease activity such as the CD Activity Index was not available. Fourth, safety outcomes, such as opportunistic or serious infections, were not investigated. Fifth, since we were not able to obtain the information from the HIRA database before 2008, medical and surgical histories before 2008 were not analyzed. Lastly, we were unable to assess the efficacy of IFX and ADA on perianal diseases because claims codes could not distinguish perianal diseases. However, we considered surgical history of perianal diseases (anal fissure, fistula, and abscess) and this factor was adjusted in our analysis. A recent Japanese study showed no significant difference in the clinical efficacy of IFX and $\mathrm{ADA}$ in the treatment of perianal fistulas in $\mathrm{CD}$, although the number of patients included was very small (31 IFX users and $16 \mathrm{ADA}$ users). ${ }^{29}$

In conclusion, this large-scale population-based study demonstrated that surgery, hospitalization, and corticosteroid use did not differ between IFX and ADA users. These findings suggest that IFX and ADA have comparable longterm effectiveness in real-life settings of biologic-naive patients with $\mathrm{CD}$. Our study may provide justification for allowing patients' and/or physicians' preferences to be an important factor when choosing between these two biologics. Our findings can help patients, physicians, and policymakers decide how to improve $\mathrm{CD}$ treatment.

\section{CONFLICTS OF INTEREST}

No potential conflict of interest relevant to this article was reported.

\section{AUTHOR CONTRIBUTIONS}

Study concept and design: Y.S.J., M.H., S.P., J.H.C. Acquisition and analysis of data: Y.S.J., M.H. Interpretation of data: Y.S.J., M.H., S.P., J.H.C. Drafting of the manuscript: Y.S.J., M.H. Overall study supervision: all authors.

\section{ORCID}

Yoon Suk Jung https://orcid.org/0000-0002-1963-7170 Minkyung Han https://orcid.org/0000-0002-5011-5557 Sohee Park https://orcid.org/0000-0001-8513-5163 Jae Hee Cheon https://orcid.org/0000-0002-2282-8904

\section{REFERENCES}

1. Lee SH, Kwon JE, Cho ML. Immunological pathogenesis of inflammatory bowel disease. Intest Res 2018;16:26-42.

2. Ooi CJ, Hilmi I, Banerjee R, et al. Best practices on immunomodulators and biologic agents for ulcerative colitis and Crohn's disease in Asia. Intest Res 2019;17:285-310.

3. Gomollon F, Dignass A, Annese V, et al. 3rd European evidence-based consensus on the diagnosis and management of Crohn's disease 2016: part 1: diagnosis and medical management. J Crohns Colitis 2017;11:3-25.

4. Hanauer SB, Feagan BG, Lichtenstein GR, et al. Maintenance infliximab for Crohn's disease: the ACCENT I randomised trial. Lancet 2002;359:1541-1549.

5. Hanauer SB, Sandborn WJ, Rutgeerts P, et al. Human antitumor necrosis factor monoclonal antibody (adalimumab) in Crohn's disease: the CLASSIC-I trial. Gastroenterology 2006;130:323-333.

6. Hazlewood GS, Rezaie A, Borman M, et al. Comparative effectiveness of immunosuppressants and biologics for inducing and maintaining remission in Crohn's disease: a network meta-analysis. Gastroenterology 2015;148:344-354.

7. Stidham RW, Lee TC, Higgins PD, et al. Systematic review with network meta-analysis: the efficacy of anti-TNF agents for the treatment of Crohn's disease. Aliment Pharmacol Ther 2014;39:1349-1362.

8. Mao EJ, Hazlewood GS, Kaplan GG, Peyrin-Biroulet L, Ananthakrishnan AN. Systematic review with meta-analysis: comparative efficacy of immunosuppressants and biologics for reducing hospitalisation and surgery in Crohn's disease and ulcerative colitis. Aliment Pharmacol Ther 2017;45:313.

9. Di Domenicantonio R, Trotta F, Cascini S, et al. Populationbased cohort study on comparative effectiveness and safety of biologics in inflammatory bowel disease. Clin Epidemiol 2018;10:203-213.

10. Osterman MT, Haynes K, Delzell E, et al. Comparative effectiveness of infliximab and adalimumab for Crohn's disease. Clin Gastroenterol Hepatol 2014;12:811-817.

11. Ananthakrishnan AN, Cagan A, Cai T, et al. Comparative effectiveness of infliximab and adalimumab in Crohn's disease and ulcerative colitis. Inflammn Bowel Dis 2016;22:880-885.

12. Singh S, Heien HC, Sangaralingham LR, et al. Comparative effectiveness and safety of anti-tumor necrosis factor agents in biologic-naive patients with Crohn's disease. Clin Gastroenterol Hepatol 2016;14:1120-1129.

13. Singh S, Andersen NN, Andersson M, Loftus EV Jr, Jess T. Comparison of infliximab with adalimumab in 827 biologicnaïve patients with Crohn's disease: a population-based Danish cohort study. Aliment Pharmacol Ther 2018;47:596-604.

14. Yen HH, Weng MT, Tung CC, et al. Epidemiological trend in 
inflammatory bowel disease in Taiwan from 2001 to 2015: a nationwide populationbased study. Intest Res 2019;17:54-62.

15. Ng WK, Wong SH, Ng SC. Changing epidemiological trends of inflammatory bowel disease in Asia. Intest Res 2016;14:111-119.

16. Jung YS, Han M, Kim WH, Park S, Cheon JH. Incidence and clinical outcomes of inflammatory bowel disease in South Korea, 2011-2014: a nationwide population-based study. Dig Dis Sci 2017;62:2102-2112.

17. Jung YS, Han M, Park S, Kim WH, Cheon JH. Cancer risk in the early stages of inflammatory bowel disease in Korean patients: a nationwide population-based study. J Crohns Colitis 2017;11:954-962.

18. Han M, Jung YS, Cheon JH, Park S. Regional variations in the use of biologics and immunomodulators among Korean patients with inflammatory bowel diseases. J Gastroenterol Hepatol 2019;34:1166-1174.

19. Bernstein CN, Loftus EV Jr, Ng SC, Lakatos PL, Moum B; Epidemiology and Natural History Task Force of the International Organization for the Study of Inflammatory Bowel Disease (IOIBD). Hospitalisations and surgery in Crohn's disease. Gut 2012;61:622-629.

20. Peyrin-Biroulet L, Loftus EV Jr, Colombel JF, Sandborn WJ. The natural history of adult Crohn's disease in populationbased cohorts. Am J Gastroenterol 2010;105:289-297.

21. Maehata Y, Nagata Y, Moriyama T, et al. Risk of surgery in patients with stricturing type of Crohn's disease at the initial diagnosis: a single center experience. Intest Res 2019;17:357364.

22. Bernstein CN, Longobardi T, Finlayson G, Blanchard JF. Direct medical cost of managing IBD patients: a Canadian population-based study. Inflamm Bowel Dis 2012;18:1498-
1508.

23. Singh S, Garg SK, Pardi DS, Wang Z, Murad MH, Loftus EV Jr. Comparative efficacy of biologic therapy in biologicnaive patients with Crohn disease: a systematic review and network meta-analysis. Mayo Clin Proc 2014;89:1621-1635.

24. Varma P, Paul E, Huang C, Headon B, Sparrow MP. A retrospective comparison of infliximab versus adalimumab as induction and maintenance therapy for Crohn disease. Intern Med J 2016;46:798-804.

25. Macaluso FS, Fries W, Privitera AC, et al. A propensity score-matched comparison of infliximab and adalimumab in tumour necrosis factor- $\alpha$ inhibitor-naïve and non-naïve patients with Crohn's disease: real-life data from the sicilian network for inflammatory bowel disease. J Crohns Colitis 2019;13:209-217.

26. Benmassaoud A, Al-Taweel T, Sasson MS, et al. Comparative effectiveness of infliximab versus adalimumab in patients with biologic-naïve Crohn's disease. Dig Dis Sci 2018;63:1302-1310.

27. Narula N, Kainz S, Petritsch W, et al. The efficacy and safety of either infliximab or adalimumab in 362 patients with anti-TNF- $\alpha$ naïve Crohn's disease. Aliment Pharmacol Ther 2016;44:170-180.

28. Sussman DA, Kubiliun N, Mulani PM, et al. Comparison of medical costs among patients using adalimumab and infliximab: a retrospective study (COMPAIRS). Inflamm Bowel Dis 2012;18:2043-2055.

29. Ji CC, Takano S. Clinical efficacy of adalimumab versus infliximab and the factors associated with recurrence or aggravation during treatment of anal fistulas in Crohn's disease. Intest Res 2017;15:182-186. 